\title{
Help-seeking Following Termination of Pregnancy after Diagnosis of Fetal Anomaly: Women's Intentions and Experiences 1 to 7 Years after the Event
}

\section{Suche nach Hilfe nach einem Schwangerschaftsabbruch bei Diagnose einer fetalen Fehlbildung: Absichten und Erfahrungen von betroffenen Frauen 1 bis 7 Jahre nach dem Abbruch}

\section{(ㄷ)(1) (웅}

Authors

Franz Hanschmidt ${ }^{1}$, Rahel Hoffmann ${ }^{1}$, Johanna Klingner ${ }^{1}$, Anette Kersting ${ }^{1}$, Holger Stepan ${ }^{2}$

Affiliations

1 Department of Psychosomatic Medicine, University of Leipzig, Leipzig, Germany

2 Department of Obstetrics, University of Leipzig, Leipzig, Germany

Key words

abortion, fetal anomaly, gynecology, help-seeking

Schlüsselwörter

Schwangerschaftsabbruch, fetale Anomalie, Gynäkologie, Suche nach Hilfe

received $\quad 27.10 .2017$

revised $\quad 5.1 .2018$

accepted 5.1.2018

Bibliography

DOI https://doi.org/10.1055/s-0044-100380

Geburtsh Frauenheilk 2018; 78: 160-166 @ Georg Thieme

Verlag KG Stuttgart · New York | ISSN 0016-5751

Correspondence

Franz Hanschmidt

Department of Psychosomatic Medicine, University of Leipzig

Semmelweisstraße 10, 04103 Leipzig, Germany

franz.hanschmidt@medizin.uni-leipzig.de

\section{ABSTRACT}

Introduction Diagnosis of fetal anomaly and the difficult circumstances involved in the decision to terminate an affected pregnancy can go along with severe psychological distress. However, little is known about women's help-seeking for emotional problems following an abortion after diagnosis of fetal anomaly.

Methods 148 women who had been treated for abortion after diagnosis of fetal anomaly at the University Hospital
Leipzig responded to self-report questionnaires 1 to 7 years after the event. Main outcomes were help-seeking intentions and actual help-seeking behavior. Logistic regression was used to explore the associations between participants' sociodemographic characteristics and help-seeking intentions.

Results Most women reported that they would seek help from their partner $(91.7 \%)$, friends/family $(82.8 \%)$ or the internet $(62.2 \%)$. With regard to health services, $50.0 \%$ of women would seek help from gynecologists and between 43.8 and $47.9 \%$ from counseling services and mental health professionals. Intentions to seek help from support groups were lowest (21.7\%). Age, income, region, and religion were associated with help-seeking intentions. Among participants with elevated levels of current psychological distress, $23.8 \%$ indicated that they had not discussed their emotional problems with a health service ever.

Conclusion Gynecologists are among the most preferred health professionals for women to discuss psychological problems in the aftermath of an abortion after diagnosis of fetal anomaly. They should be actively involved in screening, diagnostic assessment, and referral of affected women.

\section{ZUSAMMENFASSUNG}

Einleitung Die Diagnose einer fetalen Anomalie und die schwierigen Umstände, die mit der Entscheidung zusammenhängen, die Schwangerschaft abzubrechen, können eine starke psychische Belastung für betroffene Frauen darstellen. Bisher ist noch relativ wenig darüber bekannt, in welchem Maße und wo betroffene Frauen Hilfe für ihre emotionalen Probleme nach einem Schwangerschaftsabbruch bei Diagnose einer fetalen Fehlbildung suchen.

Methoden 148 Frauen, die sich nach der Diagnose einer fetalen Anomalie einem Schwangerschaftsabbruch im Universitätskrankenhaus Leipzig unterzogen, füllten zwischen 1 und 7 Jahre nach dem Abbruch einen Selbstbeurteilungsfragebogen aus. Die wichtigsten Endpunkte waren Absicht, nach Hilfe zu suchen, und tatsächliches Verhalten, um Hilfe zu bekom- 
men. Der Zusammenhang zwischen soziodemografischen Merkmalen und der Absicht, nach Hilfe zu suchen, wurde mithilfe der logistischen Regressionsanalyse untersucht.

Ergebnisse Die meisten Frauen berichteten, dass sie Hilfe bei ihrem Partner (91,7\%), bei Freunden und/oder der Familie (82,8\%) oder im Internet (62,2\%) suchen würden. Was das Gesundheitswesen anbetrifft, gaben 50,0\% der Frauen an, dass sie bei ihrem Gynäkologen Hilfe suchen würden, und zwischen 43,8 und 47.9\% der Frauen berichteten, dass sie bei einer psychologischen Beratungsstelle bzw. bei psychosozialen Fachkräften Hilfe suchen würden. Die wenigsten (21,7\%) hatten die Absicht, Hilfe bei Selbsthilfegruppen zu suchen. Es gab einen Zusammenhang zwischen Alter, Einkommen, Region und Religion und der Absicht, Hilfe zu suchen. Von den Teilnehmerinnen mit einer derzeitig erhöhten psychischen Belastung gaben $23,8 \%$ an, dass sie niemals ihre emotionalen Probleme mit einer medizinischen Fachkraft diskutiert hätten. Schlussfolgerung Gynäkologen gehören zu den bevorzugtesten Gesundheitsfachkräften, mit denen Frauen ihre psychologischen Probleme nach einem Schwangerschaftsabbruch bei Diagnose einer fetalen Fehlbildung besprechen. Gynäkologen sollten daher aktiv an der Früherkennungsuntersuchung, diagnostischen Beurteilung und Überweisung von betroffenen Frauen beteiligt sein.

\section{Introduction}

As advanced screening technologies for fetal anomalies are becoming more widely available, more women with an affected fetus face the decision about how to proceed with their pregnancy. Abortion is an option frequently chosen under particular circumstances, with large variations in abortion rates depending on the type of the anomaly. Available registry-based data allow for projections that $52.4 \%$ (95\% Cl: 37.7-66.6) of pregnancies involving a diagnosis of trisomy 21 were terminated in 2014 in Germany, compared to $6.4 \%(95 \% \mathrm{Cl}: 4.1-10.1)$ involving a diagnosis of a congenital heart defect [1]. The overall termination rate for all anomalies amounted to an estimated 4.4 abortions per 1000 births (95\% Cl: 3.5-5.4) [1]. The loss of a "normal” pregnancy implied by the diagnosis of a fetal anomaly and the complex circumstances associated with the decision to terminate the pregnancy (e.g. unsure prognosis) can be a devastating experience [2, 3]. In the aftermath of an abortion after diagnosis of fetal anomaly, women can experience grief complications as well as symptoms of posttraumatic stress and depression that sometimes persist for years [4-6]. Hence, clinical guidelines recommend that comprehensive interdisciplinary care should be available to support women receiving a diagnosis of fetal anomaly [7].

A body of literature has examined the subjective needs and experiences of care of women opting for abortion after diagnosis of fetal anomaly. Focusing largely on qualitative aspects of care, these studies suggest that women value timely and unbiased information provision, compassion and empathy from caregivers, being offered choices (for example regarding the abortion method or dealing with the baby's remains) and continuity of care [811]. While there is evidence regarding how women want to be cared for around the time of their abortion, findings on women's support needs and preferred help sources for emotional or psychological problems in the aftermath of the event remain limited. Qualitative studies indicate that women perceive a lack of aftercare, with some women making use of counseling services and support groups [3]. In a study by Ramdaney et al. [12], women cited family, friends and genetic counselors as major help sources they would use and few (5.9\%) intended to contact a grief counselor or psychologist/psychiatrist. However, a study by Korenromp et al. [13] found that $40 \%$ of the women had made contact with a psychologist four months after their abortion. Another $30 \%$ of women in the study reported that they would have endorsed help from a support group, but only a minority of those had actually made such a contact.

There is a lack of systematic investigations of women's preferred help sources for emotional support following an abortion after diagnosis of fetal anomaly, although such studies could enable health professionals to prepare for contact with affected women. Additionally, results could be used to structure care pathways in a way that they meet women's needs and to promote certain help sources. The present study set out to explore women's intentions to seek help for emotional problems in the aftermath of their abortion after diagnosis of fetal anomaly. We considered different help sources, including informal (e.g., partner, family/ friends, the internet) and formal (e.g., gynecologist, psychologist, support group). We further contrasted women's intentions to seek help to actual help-seeking in order to identify potential gaps in care pathways. We also explored associations between helpseeking intentions and demographic variables to foster understanding of individual preferences for specific help sources.

\section{Methods}

\section{Recruitment and participants}

This study presents data drawn from a cross-sectional study involving women who had undergone termination of pregnancy following the diagnosis of a fetal anomaly at the University Hospital Leipzig (Department of Obstetrics). The study was conducted between October 2015 and February 2016. In order to be included in the study, women had to be at least 18 years at the time of assessment and had to have experienced their abortion after diagnosis of fetal anomaly 1-7 years earlier. The study center's registry was searched to identify women eligible for inclusion and the head of the department contacted eligible women per mail, inviting them to participate in an anonymized study. Along with the invitation, women received extensive study information, an informed consent sheet, and the study questionnaire in German. The study was conducted according to the Declaration of Helsinki and approved by the Ethical Review Committee of the University of Leipzig. At the site of data collection, abortions after diagnosis of fetal anomaly were performed by administration of prostaglan- 
din to induce labor in conjunction with feticide if the gestational age was greater than the 22nd week.

\section{Assessment}

Participants were given several self-report questionnaires including measures of help-seeking intentions and behavior as well as measures of psychological distress.

\section{Help-seeking intentions and behavior}

Help-seeking intentions were examined by using the General Help Seeking Questionnaire (GHSQ) [14], which has been designed to measure intentions to seek help in different contexts and from different sources (7-point Likert scale: 1 = extremely unlikely to 7 = extremely likely). The first author translated the GHSQ into German and an English native speaker fluent in German translated it back into English. As recommended by the original authors, we modified instructions to match the specific situation of study participants ("If you were having a personal or emotional problem because of your late-term abortion how likely is it that you would seek help from the following people?"). Queried help sources were chosen on the basis of previous research on care structures in the context of abortions after diagnosis of fetal anomaly [13] and included formal (e.g., gynecologist, psychologist, counseling service) and informal (i.e., partner, family/friends, the internet) help sources. Participants had the opportunity to indicate additional help sources as free text response. In order to facilitate interpretation and comparison of results, responses were dichotomized, such that scores $\geq 5$ ("likely" to "extremely likely") were assigned " 1 " and all other ratings were assigned " 0 ". Participants also responded to a complementary set of binary items (yes/no) assessing whether they had actually made contact with a health service due to emotional problems associated with their abortion ("Have you ever made contact with any of the following people due to emotional/psychological problems associated with your abortion?"). For both help-seeking intentions and actual helpseeking behavior, responses to single items were additionally combined into one binary indicator of the general occurrence of help-seeking from health services. Participants who did not report any help-seeking from health services were coded as "0" and all other participants were coded as " 1 ".

\section{Psychological distress and sociodemographic variables}

Participants completed the German versions of the Inventory of Complicated Grief (ICG) $[15,16]$, the Impact of Event scale - revised (IES-R) $[17,18]$ and the Patient Health Questionaire-9 (PHQ-9) $[19,20]$ to assess symptoms of complicated grief, posttraumatic stress (PTS) and depression. Scores of $>25, \geq 39$ and $\geq 10$ indicate elevated levels of grief, PTS, and depression, respectively $[4,16,21]$. Participants also responded to self-generated questions referring to sociodemographic and obstetric characteristics as well as information on current psychological or psychiatric treatment (binary item, yes/no). Information on time of the abortion, gestational age, abortion method and type of fetal anomaly were extracted from the registry of the study center.

\section{Data analysis}

All analyses were performed using $\mathrm{R}$ [22] and results with an alpha-error probability level $<0.05$ were considered significant. Percentages including $95 \% \mathrm{Cl}$ were calculated to estimate proportions of help-seeking by help source. Among highly distressed participants (scoring above cut-off on at least one of the measures of psychological distress), proportions of help-seeking intentions and actual help-seeking were compared using McNemars mid-p test [23]. Logistic regression was applied to explore associations between sociodemographic characteristics (age at abortion, education, income, region, and religion) and intentions to seek help from health services and the internet. Time since the abortion was entered as control variable in all models.

\section{Results}

\section{Recruitment outcomes and characteristics of study participants}

A total of 395 women who had had an abortion after diagnosis of fetal anomaly between September 2008 and January 2015 were identified to be eligible for study inclusion. Valid addresses were available from 318 women, of which 148 women gave informed consent and returned the questionnaire (response rate: $46.5 \%$ ). - Table 1 shows participants' sociodemographic and obstetric profile. The majority of participants (37.2\%) was aged between 25 and 29 at the time of the abortion $(M=31.59$ years, $\mathrm{SD}=5.01$ years, range: 17.50 to 46.33 years) and most women (45.9\%) had experienced their abortion 1.08 to 3 years before participation in this study $(\mathrm{M}=3.63$ years, $\mathrm{SD}=1.88$ years, range: 1.08 to 7.42 years). The majority of participants was highly educated ( $\geq 12$ years of education: $60.8 \%$ ), lived in an urban region (57.4\%), did not have a religious affiliation (73.6\%) and had a monthly household income equal to or above 1500 Euro (74.0\%). Most of the abortions were performed in the second trimester between 15 and 26 weeks of gestation (86.5\%, M = 22.22 weeks, $\mathrm{SD}=4.45$, range: 15 to 39 ) and the most frequently diagnosed fetal anomaly was trisomy 21 (16.2\%). More than one-third of abortions $(38.5 \%)$ involved a feticide.

\section{Psychological distress and treatment}

With regard to current psychological distress, 29.7\% ( $n=44$, $95 \% \mathrm{Cl}$ : 22.6-37.9) of participants scored above the cut-off on at least one of the measures of grief, PTS or depression. Of those participants reporting elevated levels of current distress, $15.9 \%$ ( $n=7,95 \% \mathrm{Cl}: 7.2-30.7$ ) currently received psychotherapy or psychiatric treatment.

\section{Distribution of help-seeking by source}

- Table 2 provides an overview of help-seeking intentions by help sources. Between 91.7\% (95\% Cl: 85.7-95.5) and 62.2\% (95\% Cl: 53.7-70.1) of participants indicated that they would seek help from informal sources including their partner, friends/family or the internet. Regarding intentions to seek help from health services, most women (50\%, 95\% Cl: 41.9-58.1) indicated that they would contact their gynecologist in case of emotional problems. More than $40 \%$ of women would seek help from a psychologist/ 
- Table 1 Participants' sociodemographic and obstetric characteristics.

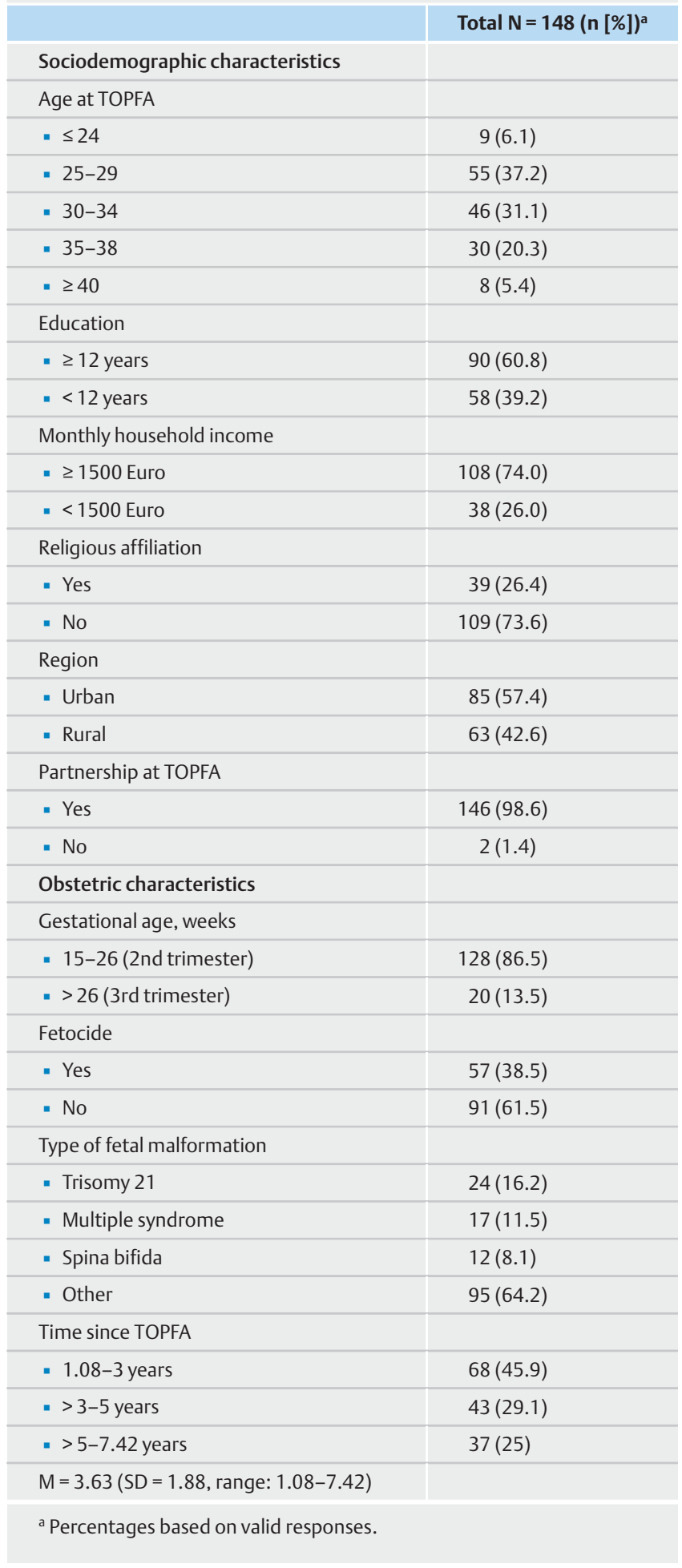

psychiatrist $(47.9 \%, 95 \% \mathrm{Cl}: 39.6-56.4)$ or counseling service (43.8\%, 95\% Cl: 35.6-52.3). Support groups were the least preferred health service $(21.7 \%, 95 \% \mathrm{Cl}$ : 15.4-29.5). Additional health services as free text responses were indicated by $7.6 \%$ (95\% Cl: 3.4-15.6) of participants and included "other affected
- Table 2 Help-seeking intentions for the full sample $(N=148)$.

\begin{tabular}{|c|c|c|}
\hline & $\mathbf{n}$ & $\begin{array}{l}\text { Intentions to seek } \\
\text { help, \% participants } \\
(95 \% \mathrm{Cl})^{\mathrm{a}}\end{array}$ \\
\hline \multicolumn{3}{|l|}{ Informal } \\
\hline - Partner & 133 & $91.7(85.7-95.5)$ \\
\hline - Friends/family (not partner) & 120 & $82.8(75.4-88.3)$ \\
\hline - Internet & 89 & $62.2(53.7-70.1)$ \\
\hline \multicolumn{3}{|l|}{ Formal (health service) } \\
\hline - Gynecologist & 72 & $50.0(41.9-58.1)$ \\
\hline - Psychologist/psychiatrist & 69 & $47.9(39.6-56.4)$ \\
\hline - Counselling service & 63 & $43.8(35.6-52.3)$ \\
\hline - General practitioner & 56 & $38.9(31-47.4)$ \\
\hline - Support group & 31 & $21.7(15.4-29.5)$ \\
\hline - Other $^{\mathrm{b}}$ & 7 & $7.6(3.4-15.6)$ \\
\hline No help from health service ${ }^{c}$ & 15 & $10.7(6.3-17.3)$ \\
\hline
\end{tabular}

women" (i.e., support group) $(n=3)$ and "midwife" $(n=2)$ (all other health services $n=1$ ). $>$ Table 3 presents the distribution of help-seeking intentions and actual help-seeking from health services among the subgroup of women experiencing current high psychological distress. Women's help-seeking intentions were not significantly different from their actual help-seeking behavior, except for help-seeking from a support group. While $33.3 \%$ (95\% Cl: 20-49.6) of women reported they would seek help from a support group, only $14.3 \%$ (95\% Cl: 5.9-29.2) had actually done so $(p=0.039)$. Responses indicated that about a quarter of the highly distressed women $(23.8 \%, 95 \% \mathrm{Cl}$ : $12.6-39.8)$ had never contacted a health service due to emotional problems related to the abortion.

\section{Associations between sociodemographic characteristics and help-seeking}

Results of the logistic regression models exploring the associations between women's sociodemographic characteristics and help-seeking intentions are presented in $>$ Table 4. Older women were less likely to seek help from a gynecologist (OR: 0.92, $95 \% \mathrm{Cl}$ : 0.85-0.99), a support group (OR: $0.88,95 \% \mathrm{Cl}: 0.79-0.97$ ) or the internet (OR: 0.93, 95\% Cl: 0.86-0.99). Women with low income, or who had a religious affiliation were less likely to seek help from a gynecologist (OR: $0.31,95 \% \mathrm{Cl}: 0.12-0.75$ and OR: 0.37, 95\% $\mathrm{Cl}$ : $0.15-0.83$, respectively), while women residing in a rural reported higher intentions to contact a gynecologist (OR: 2.36, $95 \% \mathrm{Cl}: 1.14-5.02)$.

\section{Discussion}

There is a lack of studies on women's help-seeking intentions and behavior for emotional problems in the aftermath of an abortion after diagnosis of fetal anomaly. In the present study, women 
- Table 3 Help-seeking intentions and actual help-seeking among highly distressed participants $(n=44)$.

\begin{tabular}{|c|c|c|c|c|c|}
\hline & $\mathbf{n}$ & $\begin{array}{l}\text { Intentions to seek help, } \\
\% \text { participants }(95 \% \mathrm{Cl})^{\mathrm{a}}\end{array}$ & n & $\begin{array}{l}\text { Actual help-seeking, } \\
\% \text { participants }(95 \% \mathrm{Cl})^{\mathrm{a}}\end{array}$ & p-value ${ }^{b}$ \\
\hline \multicolumn{6}{|l|}{ Formal (health service) } \\
\hline - Gynecologist & 21 & $51.2(35.4-66.8)$ & 22 & $51.2(35.7-66.4)$ & 0.804 \\
\hline - Psychologist/psychiatrist & 26 & $61.9(45.7-76)$ & 21 & $48.8(33.6-64.3)$ & 0.210 \\
\hline - Counselling service & 23 & $54.8(38.8-69.8)$ & 15 & $35.7(22-52)$ & 0.065 \\
\hline - General practitioner & 21 & $50(35.5-64.5)$ & 17 & $40.5(26-56.7)$ & 0.388 \\
\hline - Support group & 14 & $33.3(20-49.6)$ & 6 & $14.3(5.9-29.2)$ & $0.039^{*}$ \\
\hline - Other & 2 & $7.1(1.2-25.0)$ & 5 & $14.7(5.5-31.8)$ & 0.688 \\
\hline No help from health service ${ }^{c}$ & 5 & $12.5(4.7-27.6)$ & 10 & $23.8(12.6-39.8)$ & 0.289 \\
\hline
\end{tabular}

- Table 4 Associations between sociodemographic variables and help-seeking intentions.

\begin{tabular}{|l|l|l|l|l|l|l|}
\hline & Gynecologist & $\begin{array}{l}\text { Counselling } \\
\text { service }^{\mathbf{a}}\end{array}$ & $\begin{array}{l}\text { Psychologist/ }_{\text {psychiatrist }^{\mathbf{a}}} \\
\text { Model }\end{array}$ & OR $(95 \% \mathrm{Cl})$ & $\begin{array}{l}\text { General } \\
\text { practitioner }^{\mathbf{a}}\end{array}$ & Support group $^{\mathbf{b}}$ \\
\hline Time since TOPFA & $0.99(0.82-1.2)$ & $0.91(0.75-1.09)$ & $1.17(0.98-1.41)$ & $1.16(0.96-1.4)$ & $1.25(0.99-1.59)$ & $0.93(0.77-1.13)$ \\
\hline Age at TOPFA & $0.92(0.85-0.99)^{*}$ & $0.97(0.9-1.03)$ & $1.01(0.94-1.08)$ & $1.02(0.95-1.1)$ & $0.88(0.79-0.97)^{*}$ & $0.93(0.86-0.99)^{*}$ \\
\hline Education, $\geq 12$ years & $0.76(0.35-1.67)$ & $0.69(0.33-1.43)$ & $1.75(0.84-3.7)$ & $0.73(0.35-1.54)$ & $0.52(0.21-1.28)$ & $1.14(0.53-2.43)$ \\
\hline Income, low & $0.31(0.12-0.75)^{*}$ & $0.96(0.43-2.12)$ & $1.21(0.54-2.71)$ & $0.71(0.3-1.62)$ & $0.92(0.32-2.42)$ & $0.69(0.3-1.58)$ \\
\hline Region, rural & $2.36(1.14-5.02)^{*}$ & $0.97(0.48-1.93)$ & $1.16(0.58-2.32)$ & $1.11(0.55-2.23)$ & $2.04(0.85-5.03)$ & $1.16(0.57-2.38)$ \\
\hline Religion, yes & $0.37(0.15-0.83)^{*}$ & $0.88(0.4-1.93)$ & $1.15(0.53-2.5)$ & $0.66(0.28-1.48)$ & $0.55(0.16-1.57)$ & $1.15(0.51-2.65)$ \\
\hline
\end{tabular}

Listwise deletion: ${ }^{\mathrm{a}} \mathrm{n}=142,{ }^{\mathrm{b}} \mathrm{n}=141 ;{ }^{*} \mathrm{p}<0.05$.

were most likely to seek help from significant others or the internet, although the majority indicated that they would seek help from some health service. Gynecologists were the preferred health care providers for discussing potential emotional problems. Acceptance of psychologists and counseling services was also relatively high, while intentions to seek help from support groups was considerably lower. Age, income, region, and religion predicted help-seeking intentions. Long-term follow-up screening of women who have had an abortion after diagnosis of fetal anomaly appears appropriate, as about one-third of the women in this sample reported elevated levels of psychological distress 1-7 years after the event.

Results of this study suggest that gynecologists are important for the management of mental health care in the aftermath of an abortion after diagnosis of fetal anomaly. Fifty percent of all women in this study reported that they would seek help from a gynecologist in case of emotional problems, and about the same proportion of participants who experienced elevated levels of current distress had actually made such a contact. This implies that gynecologists should be prepared for delivering mental health care for affected women, especially in rural areas. The curriculum of the training for specialists in the field of gynecology and obstetrics in
Germany includes courses on issues of women's mental health [24]. However, it remains unclear whether obstetricians/gynecologists feel confident in their ability to manage the complex emotional implications of the diagnosis of a fetal anomaly and the subsequent decision for an abortion. Lafarge et al. have argued that women's experience of loss in the context of an abortion after diagnosis of fetal anomaly neither fits common clinical and social paradigms of bereavement nor abortion, which can isolate women in their grief and complicate adaption to the loss [3]. Providing gynecologists with additional information on the specific bereavement situation of women who have had an abortion after diagnosis of fetal anomaly might increase their capabilities to provide sensitive care for affected women.

Women in this study were generally inclined to contact a healthcare provider for emotional problems, including mental health professionals like psychologists/psychiatrists $(47.9 \%)$ or counseling services (43.8\%). The proportions of women intending to seek help from a health service and of those who had actually sought help were also largely comparable among participants reporting elevated levels of psychological distress. These findings are in contrast to study results by Ramdaney et al. [12], who found that only small proportions of women intended to seek help from 
mental health professionals following their abortion after diagnosis of fetal anomaly. Discrepant findings might be related to different time points of assessment. Women did not participate in this study at the time of their abortion procedure (as in Ramdaney et al. [12]), but at least one year post-procedure. Thus, women in this study may have had more time to process the initial shock of their pregnancy loss and re-evaluate their support needs as well as help-seeking intentions. However, our findings also point to potential barriers to help-seeking in the aftermath of an abortion after diagnosis of fetal anomaly. About one-quarter (23.8\%) of women who reported elevated levels of psychological distress had not discussed their emotional problems with a health service ever. Additionally, we do not know whether contact with a health service also led to the appropriate treatment. Only $15.9 \%$ of women who experienced high distress received psychotherapeutic or psychiatric treatment at the time of assessment. More research on barriers to help-seeking in the context of abortions after diagnosis of fetal anomaly is needed, but lacking resources in the healthcare sector and stigma attached to abortion and mental health issues might impair help-seeking [3, 25-27].

Gaps in immediate as well as long-term care delivery might also be related to the lack of evidence-based care protocols for providing psychological support for women in the aftermath of an abortion after diagnosis of fetal anomaly. In light of women's changing needs for support over time and their perceived lack of aftercare $[3,12]$, continuity of care should at least be offered in some way. It should be mentioned that also women who have experienced other pregnancy complications such as a pre-term birth have voiced a need for psychological support [28]. Planned follow-up visits as well as ongoing screening of women in primary gynecological care, including diagnostic assessment and referral to mental health specialists if indicated could increase the likelihood that women receive appropriate support. Women from low-income settings as well as older or religious women may require specific attention in primary gynecological care, as they were less likely to contact a gynecologist in case of emotional problems in our study. Organizing obstetric management of prenatal diagnosis and related abortions in specialized health care centers and referral of these patients to interdisciplinary teams might be another effective strategy to address gaps in care delivery during and after the procedure. Larger perinatal centers have the infrastructure allowing for the implementation of collaborative care models that integrate screening and prompt on-site referral to mental health care professionals. Care models for depression management in obstetric/gynecological clinics based on such collaborative approaches have been shown to improve women's psychological outcomes, treatment adherence, and satisfaction with care [29].

Support groups for women/parents who have experienced an abortion after diagnosis of fetal anomaly have received favorable reviews from attendees [30], but only $21.7 \%$ of women in this study intended to seek help from a support group. Moreover, in the subgroup of women experiencing psychological distress, fewer women had actually contacted a support group (14.3\%), compared to the number of women who indicated that they would make such a contact (33.3\%). Korenromp et al. [13] have made similar observations, which points to a potential gap between women's needs and the availability of support groups. However, more research on women's underlying reasons for not seeking help from support groups is warranted. Promoting support groups as an additional means of emotional support and establishing contact if wished, specifically among older women, might raise awareness and utilization of this option. Our study also identified a large potential for offering online support, as $62.2 \%$ of participants stated that they would seek help on the internet. Internet interventions have become increasingly popular and are available for bereavement populations [31,32]. Online support/discussion groups may be appealing for women who have had an abortion after diagnosis of fetal anomaly as they provide a sense of anonymity when sharing sensitive health matters. However, research indicates that women seek advice mostly from unmoderated pregnancy or pregnancy loss-related internet sites lacking evidence-based information [33]. Health professionals thus have an important role in guiding women's use and evaluation of different online resources [34].

Results of this study need to be interpreted in light of its limitations. The generalizability of results is limited as this study took place in one large clinic in eastern Germany and had a response rate of $46.5 \%$. It is possible that the support needs and experiences of non-responders differed from those of study participants, for example due to stigma associated with help-seeking. Relatedly, study participation was only possible for women with sufficient knowledge of the German language. While the dichotomization of responses to the items of the GHSQ facilitated interpretation and comparison of results, it might have artificially reduced complexity underlying women's intentions to seek help. The instruments used to assess current psychological distress do further not allow for a clinical diagnosis. Hence, the number of women who are in need of treatment according to diagnostic systems may not be accurately reflected by study results. Participants' accounts of previously contacted help sources may have been influenced by recall bias. Lastly, the queried help-sources focused largely on health professionals and were rather unspecific with regard to voluntary or non-state funded services (e.g., religious counselors). Thus, help sources in our study may have not adequately represented the whole range of possible help sources, although participants had the opportunity to indicate additional help sources as free text response.

Since gynecologists are among the most preferred health professionals for women to discuss emotional problems experienced in the aftermath of an abortion after diagnosis of fetal anomaly, these providers should be actively involved in the mental health care of affected women. This might require additional education in dealing with the specific psychological circumstances involved in the diagnosis of a fetal anomaly and the associated decision to terminate the pregnancy. Routine screening and referral of women could facilitate detection and treatment uptake also for women who are less likely to seek help. Longitudinal research is needed to understand women's changing needs for support over time. Further research is also warranted to specify barriers to help-seeking and to develop evidence-based care models ensuring longterm psychological support for women in the aftermath of the event. 


\section{Acknowledgements}

The authors would like to thank all study participants for their time and investment in the study.

\section{Conflict of Interest}

The authors declare that they have no conflict of interest.

\section{References}

[1] EUROCAT. EUROCAT Website Database. 2017. Online: http://www. eurocat-network.eu/ACCESSPREVALENCEDATA/PrevalenceTables; last access: 25.07.2017

[2] Statham H. Prenatal diagnosis of fetal abnormality: the decision to terminate the pregnancy and the psychological consequences. Fetal Matern Med Rev 2002; 13: 213-247

[3] Lafarge C, Mitchell K, Fox P. Termination of pregnancy for fetal abnormality: a meta-ethnography of women's experiences. Reprod Health Matters 2014; 22: 191-201

[4] Korenromp M], Christiaens GC, van den Bout J et al. Long-term psychological consequences of pregnancy termination for fetal abnormality: a cross-sectional study. Prenat Diagn 2005; 25: 253-260

[5] Kersting A, Dorsch M, Kreulich C et al. Trauma and grief 2-7 years after termination of pregnancy because of fetal anomalies-a pilot study. J Psychosom Obstet Gynecol 2005; 26: 9-14

[6] Davies V, Gledhill J, McFadyen A et al. Psychological outcome in women undergoing termination of pregnancy for ultrasound-detected fetal anomaly in the first and second trimesters: a pilot study. Ultrasound Obstet Gynecol 2005; 25: 389-392

[7] Woopen C. Beratung bei Präimplantations- und Pränataldiagnostik. Bundesgesundheitsblatt Gesundheitsforschung Gesundheitsschutz 2013; 56: $269-276$

[8] McCoyd JLM. What do women want? Experiences and reflections of women after prenatal diagnosis and termination for anomaly. Health Care Women Int 2009; 30: 507-535

[9] Asplin N, Wessel H, Marions L et al. Pregnancy termination due to fetal anomaly: women's reactions, satisfaction and experiences of care. Midwifery 2014; 30: 620-627

[10] Geerinck-Vercammen CR, Kanhai HH. Coping with termination of pregnancy for fetal abnormality in a supportive environment. Prenat Diagn 2003; 23: 543-548

[11] Fisher J, Lafarge C. Women's experience of care when undergoing termination of pregnancy for fetal anomaly in England. J Reprod Infant Psychol 2015; 33: 69-87

[12] Ramdaney A, Hashmi SS, Monga M et al. Support desired by women following termination of pregnancy for a fetal anomaly. J Genet Couns 2015; 24: 952-960

[13] Korenromp M], Page-Christiaens GC, van den Bout ] et al. Maternal decision to terminate pregnancy in case of Down syndrome. Am J Obstet Gynecol 2007; 196: 149.e1-149.e11

[14] Wilson C], Deane FP, Ciarrochi J et al. Measuring help-seeking intentions: properties of the general help seeking questionnaire. Can J Couns Psychother Rev Can Couns Psychothérapie 2007; 39: 15-28

[15] Lumbeck MB. Erstvalidierung der deutschen Version des „Inventory of Complicated Grief“ (ICG-D). Z Fuer Klin Psychol Psychother 2012; 41: 243-248
[16] Prigerson HG, Maciejewski PK, Reynolds CF et al. Inventory of Complicated Grief: a scale to measure maladaptive symptoms of loss. Psychiatry Res 1995; 59: 65-79

[17] Maercker A, Schützwohl M. Erfassung von psychischen Belastungsfolgen: Die Impact of Event Skala-revidierte Version (IES-R). Diagnostica 1998; 44: 130-141

[18] Weiss DS, Marmar CR. The Impact of Event Scale - revised. In: Wilson JP, Keane TM, eds. Assessing psychological Trauma and PTSD. New York: Guilford; 1997: 399-411

[19] Kroenke K, Spitzer RL, Williams JB. The PHQ-9: validity of a brief depression severity measure. J Gen Intern Med 2001; 16: 606-613

[20] Löwe B, Spitzer RL, Zipfel S, Herzog W. Gesundheitsfragebogen für Patienten (PHQ D). Komplettversion und Kurzform. Testmappe mit Manual, Fragebögen, Schablonen. 2. Aufl. Karlsruhe: Pfizer; 2002

[21] Busch MA, Maske UE, Ryl L et al. [Prevalence of depressive symptoms and diagnosed depression among adults in Germany: results of the German Health Interview and Examination Survey for Adults (DEGS1)]. Bundesgesundheitsblatt Gesundheitsforschung Gesundheitsschutz 2013; 56: 733-739

[22] R Development Core Team. R: A language and environment for statistical computing. Vienna, Austria: R Foundation for Statistical Computing; 2016

[23] Fagerland MW, Lydersen S, Laake P. The McNemar test for binary matched-pairs data: mid-p and asymptotic are better than exact conditional. BMC Med Res Methodol 2013; 13: 91

[24] Bundesärztekammer. (Muster-)Richtlinien über den Inhalt der Weiterbildung (MWBO 2003). 2011. Online: http://www.bundesaerztekammer. de/fileadmin/user_upload/downloads/RiliMWBO20110218.pdf; last access: 04.01.2018

[25] Berger M. Die Versorgung psychisch Erkrankter in Deutschland - Unterbesonderer Berücksichtigung des Faches „Psychiatrie und Psychotherapie“. In: Berger M, Fritze J, Roth-Sackenheim C, Voderholzer U, Hrsg. Die Versorgung psychischer Erkrankungen in Deutschland. Berlin, Heidelberg: Springer; 2005: 3-18

[26] Hanschmidt F, Linde K, Hilbert A et al. Abortion stigma: a systematic review. Perspect Sex Reprod Health 2016; 48: 169-177

[27] Button S, Thornton A, Lee $S$ et al. Seeking help for perinatal psychological distress: a meta-synthesis of women's experiences. $\mathrm{Br} J$ Gen Pract 2017; 67: e692-e699

[28] Jotzo M, Schmitz B. Traumatisierung der Eltern durch die Frühgeburt des Kindes. Psychotraumatologie 2002; 3: 38

[29] Melville JL, Reed SD, Russo J et al. Improving care for depression in obstetrics and gynecology: a randomized controlled trial. Obstet Gynecol 2014; 123: 1237-1246

[30] Gordon L, Thornton A, Lewis S et al. An evaluation of a shared experience group for women and their support persons following prenatal diagnosis and termination for a fetal abnormality. Prenat Diagn 2007; 27: 835-839

[31] Dyer KA, Thompson CD. Internet use for web-education on the overlooked areas of grief and loss. Cyberpsychol Behav 2000; 3: 255-270

[32] Kersting A, Dölemeyer R, Steinig J et al. Brief internet-based intervention reduces posttraumatic stress and prolonged grief in parents after the loss of a child during pregnancy: a randomized controlled trial. Psychother Psychosom 2013; 82: 372-381

[33] Hodgson J, Pitt P, Metcalfe $S$ et al. Experiences of prenatal diagnosis and decision-making about termination of pregnancy: a qualitative study. Aust N Z J Obstet Gynaecol 2016; 56: 605-613

[34] Lagan BM, Sinclair M, Kernohan WG. Internet use in pregnancy informs women's decision making: a web-based survey. Birth 2010; 37: 106-115 